\title{
COVID, resilience, and the built environment
}

\author{
Jesse M. Keenan ${ }^{1}$ (D) \\ Published online: 14 May 2020 \\ (c) Springer Science+Business Media, LLC, part of Springer Nature 2020
}

\begin{abstract}
This article provides a perspective on the reciprocal relationships between public and private sector resilience planning activities and the ongoing COVID responses in the U.S. Through the lens of the built environment, this article provides selected insights into how various disaster, organizational, and engineering resilience activities have likely positively shaped COVID responses within the healthcare sector. These positive influences are contextualized within extensive efforts within public health and healthcare management to calibrate community resilience frameworks and practices for utilization in everything from advancing community health to the continuity of facilities operations. Thereafter, the article shifts focus to speculate on how ongoing experiences under COVID might yield positive impacts for future resilience designs, plans and policies within housing and the built environment. Through this perspective, the article hopes to explore those often overlooked aspects of the physical and social parameters of the built environment that may be understood as providing opportunities to inform future disaster, public health, and climate change preparations and responses.
\end{abstract}

Keywords COVID-19 $\cdot$ Resilience $\cdot$ Disaster resilience $\cdot$ Community resilience $\cdot$ Built environment $\cdot$ Housing

\section{Introduction}

Climate change and the novel Coronavirus ("COVID") have much in common. Like climate change, the COVID pandemic was widely anticipated among public health officials and medical scientists for decades (Kleinman and Watson 2006; Yang et al. 2020). Among climate change experts, the risks of infectious disease and pandemics have long been on the list of multi-hazards to anticipate (Semenza and Menne 2009) and to observe (Caminade et al. 2019). Indeed, some of the planning associated with the next anticipated Coronavirus pandemic has laid the foundation for ongoing treatment and vaccine advancements being made on a near weekly basis. Yet, for the most part, the risks from any number of potential - and even likely_-pandemics have been broadly ignored by the general public and policy makers for decades-despite the science, despite the warnings. There is nothing new here-it's the same old story from precautionary principles (or lack thereof) to the behavioral and cognitive limitations to risk assessment and prioritization

Jesse M. Keenan

jkeenan@tulane.edu

1 School of Architecture, Tulane University, New Orleans, USA
(Sunstein 2006). In this regard, COVID and climate change are societal outcasts too ugly to standout and too deadly to ignore. Yet, in our responses to both, they share a common linkage that offers an opportunity to reflect on where we have been and we are going within the allied fields of resilience and adaptation.

This article provides a perspective on the reciprocal relationships between public and private sector resilience planning activities and the ongoing COVID responses in the U.S. Through the lens of the built environment, this article provides selected insights into how various disaster, organizational, and engineering resilience activities have likely positively shaped COVID responses within the healthcare sector. These positive influences are contextualized within extensive efforts within public health and healthcare management to calibrate community resilience frameworks and practices for utilization in everything from advancing community health to the continuity of facilities operations. Thereafter, the article shifts focus to speculate on how ongoing experiences under COVID might yield positive impacts for future resilience designs, plans and policies within housing and the built environment. Through this perspective, the article hopes to explore those often overlooked aspects of the physical and social parameters of the built environment that may be understood as providing opportunities to inform 
future disaster, public health, and climate change preparations and responses.

\section{Resilience planning informs COVID response}

There are a number of primary categories associated with different variants of resilience that have their own independent conceptual and analytical frameworks - there is no one type of 'resilience' (Davidson et al. 2016; Moser et al. 2019). Among the categorical variants of resilience, it is 'disaster' and 'engineering' resilience that are most widely utilized in domestic multi-hazard and climate change planning in the U.S. (Keenan 2018). Within these planning activities there is increasing sophistication in separating 'risk' and 'resilience' as independent, but related, domains of management and policy (Linkov et al. 2018a, b). While there is not a uniform consensus across fields of scholarship and practice, as a general matter, risk is relegated to responding and preparing (i.e., mitigation, transfer, etc.) for known phenomena based on a relatively stationary probabilistic outcomes, and resilience is primarily oriented to capacities that address both known and unknown phenomena representing a broad spectrum of probability and uncertainty in comparatively fluid and dynamic conditions and responses (Linkov et al. 2018a, b). In this sense, resilience is critically important for filling the void left by risk management that is limited to probability - particularly as it relates to low probability or highly uncertain, high impact events such as COVID.

In its most simplified distillation, 'engineering' resilience (and to a large extent 'disaster' resilience) speaks to the elastic and reversionary capacities of a system to return to pre-stimulus level of operational performance and material quality, which may ultimately lead to adaptive and maladaptive outcomes depending on aging effects and the associated costs of time and money in supporting such performance (Hosseini et al. 2016; Kurth et al. 2019). Engineering resilience is descriptive and may be readily designed and observed in a variety of engineered systems, including a variety of infrastructure systems and sectors (Bostick et al. 2018). On the other end of the spectrum of categorical resilience is 'community' resilience, which speaks to the capacity of communities-a collection of individuals and social organizations-to respond, recover and accommodate external shocks and stresses (MatarritaCascante et al. 2017). By contrast to engineering resilience, the measurement of community resilience is still at an early stage (Sharifi 2016; Cutter 2016) and current practices in community resilience are largely normative in favor of subject judgements about how communities ought to prepare for and respond to ongoing challenges (Patel et al. 2017). Although there are other important categories, such as 'ecological' and 'organizational' resilience, engineering and community resilience have been the primary drivers in U.S. resilience planning activities in the built environment in the past decade.

While advancements in the framing and measurement of community resilience have been popular in the literature as a free-standing largely normative exercise, in practice, much of this work has operated to provide a social and human dimension to the operations of disaster and engineering resilience among emergency management institutions (NIST 2015; Koliou et al. 2017). While there are known limitations to emergency management's ability to challenge structural institutions that define long-term vulnerabilities to climate change (Gillard 2016), COVID is the type of shock that fits within emergency management's multi-hazard framework (Djalante et al. 2020). In the past decade, multi-hazard disaster and engineering resilience planning has had significant impacts in shaping the design and management of the built environment in everything from supporting the business continuity of private enterprise (Keenan 2015) to the sustainable provision of critical public services (Humphries 2019).

Over the past decade, public health officials have actively participated in the diffusion of disaster and community resilience planning practices alongside their colleagues in emergency management, urban planning, and civil engineering. Mass casualty preparations in recent years in the U.S. have largely centered on gun violence under a different policy regime within homeland security in the age of terrorism and mass shootings (Melmer et al. 2019). However, disaster resilience planning activities have more broadly engaged both public and private health systems to look inward in terms of internal communications and business continuity; critical facilities and operations assessments; and multi-network contingency planning (Zhong et al. 2014; Verheul and Dückers 2020). The urgency of this work was well amplified with the high-profile loss and evacuation of NYU Langone Medical Center in New York City during Hurricane Sandy in 2012-a major center of healthcare for much of Manhattan (Powell et al. 2012; Seltenrich 2018). In the years that followed, healthcare systems from across the country have been actively preparing for a variety of hazards, including those associated with climate change impacts (USCRT 2016). By the time Hurricane Harvey hit Houston in 2017, the sector had a new champion in the Texas Medical Center, which has served as the quintessential case study for engineering and operational resilience capacities (Flynn 2018). It is worth recognizing that the motivation for such resilience investments is partially driven by the potential for superior health outcomes, but it is also a function of the economic losses that resonate well beyond facilities repair and replacement (Desai et al. 2019). 
Engineering resilience models and techniques have informed nearly every aspect of facilities design and management from dry flood proofing of critical equipment (Chand and Loosemore 2016a, b; Bignami et al. 2019) to real-time intelligence of surface transportation for managing vehicle traffic (Tariverdi et al. 2019). Beyond facilities, healthcare firms have also benefited from organizational resilience efforts to prepare for alternative supply chains and procurements models (Mandal 2017). But, disaster resilience 'thinking' also forced hospital and healthcare networks to evaluate the adaptive capacity of their building designs to handle multiple types of programs and alternative configurations (Aghapour et al. 2019). We see the benefits of this today with the expansion of intensive care units ("ICU") into other parts of hospital facilities, as well as the coordination between in-hospital care and the utilization of portable mass care facilities. By another measure, the rapid deployment of telemedicine may very well challenge the future utility of some medical facilities, even if that ultimately means something like smaller waiting rooms in family practice offices (AlDossary et al. 2017). In the broader national effort to cut healthcare costs, every square foot counts. In addition, as healthcare networks have expanded into a hub and spoke model for outpatient care, these outpatient facilities have turned into what used to be the purpose of neighborhood public health facilities - they have become, in some cases, a critical access points for COVID testing and triaging (Elrod and Fortenberry 2017). In some cases, a CVS pharmacy is doing what a county public health facility used to do (Repko 2020).

While a replacement of public health facilities with private healthcare facilities is not a particularly defensible model, this ad hoc utilization amplifies the proposition of several U.S. cities, including Miami, for the development of local 'resilience hubs' that can serve as a physical platform for deploying public health, food, information and other resources for communities in good times and in bad (City of Miami 2020). Unfortunately, such 'hubs' are not currently considered critical facilities under U.S. Department of Homeland Security ("DHS") rules and are therefore ineligible for funding under a number of programs. Perhaps moving forward, reinvestment in community public health facilities through DHS programs could serve a variety of public health and disaster and community resilience co-benefits. Indeed, public health scholars and practitioners have made considerable advances in operationalizing community resilience.

In a post-Cutter landscape of indeterminate quantitative socioeconomic resilience indicators (Burton 2015) that are limited in their replicability and scalability within existing policy pathways (Cutter and Derakhshan 2019), public health has stepped-up to advance a mix of quantitative and qualitative community resilience indicators that tell a broader story of community health that is central to our physical and mental capacity to endure climate change and other public health crises (WHO 2018). Indeed, public health has squarely captured the attention of public policy makers by arguing that community resilience is central to offsetting existing inequitable disparities in accessing the U.S. healthcare system (Lichtveld 2018). But, these advancements have come in all sorts of shapes and sizes. At a truly community scale, there is little doubt that community gardens started by public health and civic ecology advocates in the name of community resilience will be providing fresh, healthy food for families struggling with COVID this summer (Shimpo et al. 2019). Perhaps community gardens and resilience hubs should both be added to the DHS critical facilities list-along with pharmacies, grocery stores and other facilities that are truly critical for social welfare and life-safety.

\section{COVID informs future resilience planning}

Aside from an expanded list of critical facilities, the COVID crisis offers insights into a variety of vulnerabilities, coping strategies, and an ad hoc interventions that offer insight into future resilience planning and design activities. It is widely acknowledge that resilience is generally advanced in institutional terms each time that a government or a community has an experience with a disaster-there is always something to be learned (Young 2010; Henly-Shepard et al. 2015). Another recent disaster-the foreclosure crisis (2008-2011) during the Great Recession—led to a number of legislative reforms that identified financial risks at the household level and across the housing financing system. These reforms sought to mitigate and manage a variety of risks that are yielding benefits today. One could argue that they have advanced the specific resilience of the housing economy. Beyond risk transfer mechanisms in the capital markets and the elimination of highly risky loans, banks and mortgage servicers are much more reluctant to foreclose recognizing that the weight of the empirical evidence suggests that alternative work-outs are far more effective in maintaining the asset value of mortgages and housing collateral. Whether it is loan forbearance or debt reduction, these lessons have since helped local housing markets stabilize following countless hurricanes and forest fires in the past decade (Gallagher and Hartley 2017). In the coming years, we will likely also have a much better sense of what works and what does not work in light of current congressionally allocated emergency subsidies and their effect in stabilizing local economies and housing markets. In particular, we are currently undergoing the most widespread set of experiments in rental housing stabilization ever undertaken and the lessons from this will likely shape future resilience and 
post-disaster recovery efforts that engage housing stabilization for generations to come.

So, the question remains: what are we learning about our use and design of the built environment today in the midst of the COVID crisis that might shape future resilience efforts? The intimacy of social isolation has afforded us the luxury of seeing and experiencing our built environment in a very different way. From the lower occupancy rates of grocery stores to the social spaces partitioned within even a single room, there is much to be explored. Most immediately, building managers are actively developing infectious disease control protocols for operating and cleaning buildings. They are thinking about weak links in HVAC systems, filtration standards, and the prospects for transmission in common areas (NMHC 2020). These emerging practices are also likely to advance greater attentiveness to indoor air quality as people spend significantly more time inside than usual. Other adaptations are perhaps less applicable, such as new signage requiring single occupancy elevator rides. Yet, other mundane challenges associated with providing access to quarters for coin operated laundry serving tens of millions of American renters may be a key preparation in the future. While resilience techniques for multi-family buildings are comparatively mature, additional operational and performance standards are likely to originate from COVID (Schoeman 2015).

The design of residential housing is a reflection of our cultural construction of home and its domestic attributes. The domestic realities—good and bad-are compressed in time and spaces over the course of disasters. What happens when long periods of isolation leads to domestic violence? Perhaps a resilience standard might require the installation of locks on interior doors. Ensuring safe spaces might actually require the design of safe spaces. The intimacy of social relationships also plays out for families who are remotely working in spaces designed almost exclusively for entertainment, leisure and domestic pursuits. This requires new forms of multi-purpose furniture and adaptive swing spaces where eating, working and study spaces overlap. While consumer design preferences are unlikely to overcorrect to the COVID experience, there are subtle adaptations that are likely to be positive. People are more sensitive to storage and their overall consumption. They are finding ways to recycle materials and fix things that they might have otherwise simply replaced. This economization of material speaks to social learning that is likely to have a positive impact on the resilience of the built environment when the next disaster strikes. Just in terms of disaster preparedness, many families will now not only have stockpiles of food and medicine, they will also have things like home medical diagnostic equipment (e.g., iPhone compatible portables EKG devices) and home school education materials. All of these preparations are critically important, especially at a time when COVID is significantly weakening our national emergency response capacities for hurricanes, floods, forest fires and other labor intensive disasters.

Beyond the household, the novel experiences with the built environment are extending into streetscapes, parks and other forms of public space. Times of disaster do intensify out biophilic behaviors, but they also highlight the fundamental values associated with investments in public space and the natural environment (Tidball 2012). With many fewer cars on the streets, a new civic realm may be envisioned that supports a more sustainable worldview of the built environment, including what it means to have a reduction in health impacts associated with air pollution (Dutheil et al. 2020). These renewed landscapes are the grounds where people are mobilizing new commitments for physical exercise-once speculated to be a major indicator of community resilience by the U.S. government (FEMA 2016). Like New Year's resolutions, these behaviors are likely to fade in a post-COVID recovery. Yet, they offer valuable insight into where priorities for resilience should be defined and the role that the built environment plays in supporting those priorities.

\section{Conclusions}

Learning from disasters is critical. In the heat of the moment, we have the opportunity to observe what is working and what is not working - and for whom. As this article highlights, existing COVID responses have likely benefited from recent resilience planning efforts largely advanced in the name of addressing climate change and disaster mitigation. In particular, public health and healthcare management contributions to a broader interdisciplinary field of inquiry associated with community resilience have likely translated into meaningful action that could very well reciprocally advance resilience activities in other sectors. Specific to the healthcare sector, considerations relating to the resilience and adaptive capacity of the built environment are central to managing the existing challenges associated with supply constraints, alternative forms of service delivery, and the broader continuity of operations. In the linkage between prior disaster experience-some of which are attributable to climate change impacts - and COVID, we find a measure of maturity in the human health and healthcare sectors that provides hope for the progressive development of core practices and strategies associated with disaster, organizational and engineering resilience.

The COVID experience has also imposed new perspectives on the role housing and the built environment can serve in shaping resilience interventions and capacities as viewed through the lens of domiciliaries, consumers, and civic actors. From the management of social space to disaster 
preparedness, the built form is a conduit for shaping positive behaviors that are the heart of any framework for community resilience. While some ad hoc COVID responses will soon fade, others will sustain as part of our collective adaptive capacity for addressing future social and environmental shocks and stresses. In these times of crisis, it is worth recognizing that the future of research and practice across various domains of resilience and adaptation will be defined not only by the quantifications of socioeconomic indicators but also by the qualification of the human experience in all its capacities for ingenuity, empathy, and moral responsibility. Whether it is the advancement of human health or the design of architecture and the built environment, we are reminded that learned resilience is a uniquely human endeavor.

\section{Compilance with ethical standards}

Conflict of interest The author declares that they have no conflicts of interest.

\section{References}

Aghapour AH, Yazdani M, Jolai F, Mojtahedi M (2019) Capacity planning and reconfiguration for disaster-resilient health infrastructure. J Build Eng 26:100853. https://doi.org/10.1016/j. jobe. 2019.100853

AlDossary S, Martin-Khan MG, Bradford NK, Smith AC (2017) A systematic review of the methodologies used to evaluate telemedicine service initiatives in hospital facilities. Int J Med Inform 97:171-194. https://doi.org/10.1016/j.ijmedinf.2016.10.012

Bignami DF, Rosso R, Sanfilippo U (2019) Flood proofing in urban areas. Springer, Cham

Bostick TP, Connelly EB, Lambert JH, Linkov I (2018) Resilience science, policy and investment for civil infrastructure. Reliabil Eng Syst Saf 175(1):19-23

Burton CG (2015) A validation of metrics for community resilience to natural hazards and disasters using the recovery from Hurricane Katrina as a case study. Ann Assoc Am Geogr 105(1):67-86. https ://doi.org/10.1080/00045608.2014.960039

Caminade C, McIntyre KM, Jones AE (2019) Impact of recent and future climate change on vector-borne diseases. Ann N Y Acad Sci 1436(1):157-173. https://doi.org/10.1111/nyas.13950

Chand AM, Loosemore M (2016a) Hospital learning from extreme weather events: using causal loop diagrams. Build Res Inf 44(8):875-888

Chand AM, Loosemore M (2016b) Hospital disaster management's understanding of built environment impacts on healthcare services during extreme weather events. Eng Constr Architect Manage 23(2):385-402. https://doi.org/10.1108/ECAM-05-2015-0082

City of Miami (2020) Miami forever climate ready plan. Office of the Chief Resilience Officer, City of Miami, Miami. https://www. miamigov.com/Government/MiamiForeverClimateReady

Cutter SL (2016) The landscape of disaster resilience indicators in the USA. Nat Hazards 80(2):741-758

Cutter SL, Derakhshan S (2019) Implementing disaster policy: exploring scale and measurement schemes for disaster resilience. $\mathrm{J}$ Homel Secur Emerg Manag. https://doi.org/10.1515/jhsem $-2018-0029$
Davidson J, Jacobson C, Lyth A, Dedekorkut-Howes A, Baldwin C, Ellison J, Holbrook N, Howes M, Serrao-Neumann S, SinghPeterson L, Smith T (2016) Interrogating resilience: toward a typology to improve its operationalization. Ecol Soc 21(2):27

Desai SP, Harris CA, Gordon J (2019) The economic impact of hurricane evacuations on a Coastal Georgia Hospital: a case study. Front Public Health 7:149. https://doi.org/10.3389/fpubh .2019 .00149

Djalante R, Shaw R, DeWit A (2020) Building resilience against biological hazards and pandemics: COVID-19 and its implications for the Sendai framework. Prog Disaster Sci. https://doi. org/10.1016/j.pdisas.2020.100080

Dutheil F, Baker JS, Navel V (2020) COVID-19 as a factor influencing air pollution? Environ Pollut. https://doi.org/10.1016/j.envpo 1.2020 .114466

Elrod JK, Fortenberry JL (2017) The hub-and-spoke organization design: an avenue for serving patients well. BMC Health Serv Res 17(1):25-33. https://doi.org/10.1186/s12913-017-2341-x

Gallagher J, Hartley D (2017) Household finance after a natural disaster: the case of Hurricane Katrina. Am Econ J 9(3):199-228. https ://doi.org/10.1257/pol.20140273

Gillard R (2016) Questioning the diffusion of resilience discourses in pursuit of transformational change. Glob Environ Politics 16(1):13-20

Federal Emergency Management Agency (FEMA) (2016). Draft interagency concepts of community resilience indicators and nationallevel measures. U.S. Department of Homeland Security, Washington, DC. https://www.fema.gov/media-library-data/1466085676 217-a14e229a461adfa574a5d03041a6297c/FEMA-CRI-Draft -Concept-Paper-508_Jun_2016.pdf

Flynn, S. (2018). Higher ground: the sophisticated healthcare response of the Southeast Texas regional advisory council to Hurricane Harvey. The Global Resilience Institute, Northeastern University/South East Texas Regional Advisory Council, Boston, MA. https://globalresilience.northeastern.edu/app/uploads/2020/01/ The-Sophisticated-Healthcare-Response-of-the-SouthEast-Texas -Regional-Advisory-Council-to-Hurricane-Harvey.pdf

Henly-Shepard S, Gray SA, Cox LJ (2015) The use of participatory modeling to promote social learning and facilitate community disaster planning. Environ Sci Policy 45:109-122. https://doi. org/10.1016/j.envsci.2014.10.004

Hosseini S, Barker K, Ramirez-Marquez JE (2016) A review of definitions and measures of system resilience. Reliabil Eng Syst Saf 145:47-61

Humphries BE (2019) Critical infrastructure: emerging trends and policy considerations for congress. R45809. Congressional Research Service, Washington, DC

Keenan JM (2015) From sustainability to adaptation: a case study of Goldman Sach's corporate real estate strategy. Build Res Inf 43(6):407-422. https://doi.org/10.1080/09613218.2016.1085260

Keenan JM (2018) Types and forms of resilience in local planning in the US: who does what? Environ Sci Policy 88:116-123. https:// doi.org/10.1016/j.envsci.2018.06.015

Koliou M, van de Lindt JW, McAllister TP, Ellingwood BR, Dillard M, Cutler H (2017) State of the research in community resilience: progress and challenges. Sustain Resilient Infrastruct. https://doi. org/10.1080/23789689.2017.1418547

Kleinman A, Watson JL (2006) SARS in China: prelude to pandemic?. Stanford University Press, Palo Alto, CA.

Kurth M, Keenan JM, Sasani M, Linkov I (2019) Defining resilience for the US building industry. Build Res Innov 47(4):480-492

Lichtveld M (2018) Disasters through the lens of disparities: elevate community resilience as an essential public health service. Am J Public Health. https://doi.org/10.2105/AJPH.2017.304193 
Linkov I, Fox-Lent C, Read L, Allen CR, Arnott JC, Bellini E, Hynes W (2018a) Tiered approach to resilience assessment. Risk Anal 38(9):1772-1780. https://doi.org/10.1111/risa.12991

Linkov I, Trump BD, Keisler J (2018b) Risk and resilience must be independently managed. Nature 555:7694. https://doi. org/10.1038/d41586-018-02567-0

Mandal S (2017) The influence of organizational culture on healthcare supply chain resilience: moderating role of technology orientation. J Bus Ind Mark 32(8):1021-1037. https://doi.org/10.1108/ JBIM-08-2016-0187

Matarrita-Cascante D, Trejos B, Qin H, Joo D, Debner S (2017) Conceptualizing community resilience: revisiting conceptual distinctions. Community Dev 48(1):105-123

Melmer P, Carlin M, Castater CA, Koganti D, Hurst SD, Tracy BM, Sciarretta JD (2019) Mass casualty shootings and emergency preparedness: a multidisciplinary approach for an unpredictable event. J Multidiscipl Healthc 12:1013-1021. https://doi. org/10.2147/JMDH.S219021

Moser S, Meerow S, Arnott J, Jack-Scott E (2019) The turbulent world of resilience: interpretations and themes for transdisciplinary dialogue. Clim Chan 153(1):21-40. https://doi.org/10.1007/s1058 4-018-2358-0

National Institutes of Standards and Technology (2015) Community resilience planning guide for buildings and infrastructure systems, vol 1. U.S. Department of Commerce, Washington, DC. 10.6028/ NIST.SP.1190v1

National Multifamily Housing Council (2020) Coronavirus preparedness for apartment firms. National Multifamily Housing Council, Washington, DC. https://www.nmhc.org/research-insight/analysisand-guidance/emergency-preparedness/coronavirus-preparedne ss-for-apartment-firms/

Patel SS, Rogers MB, Amlôt R, Rubin GJ (2017) What do we mean by 'community resilience'? A systematic literature review of how it is defined in the literature. PLoS Curr 9

Powell T, Hanfling D, Gostin LO (2012) Emergency preparedness and public health: the lessons of Hurricane Sandy. J Am Med Assoc 308(24):2569-2570. https://doi.org/10.1001/jama.2012.108940

Repko M (2020) CVS and Walgreens are opening more drive-thru coronavirus testing sites. Here's what to expect if you go. CNBC. https://www.cnbc.com/2020/04/09/what-to-expect-if-go-to-adrive-thru-coronavirus-test-site.html. Accessed 9 April 2020

Schoeman L (2015) Ready to respond: strategies for multifamily building resilience. Enterprise Community Partners, Washington, DC. https://www.enterprisecommunity.org/resources/ready-respondstrategies-multifamily-building-resilience-13356

Sharifi A (2016) A critical review of selected tools for assessing community resilience. Ecol Ind 69:629-647
Semenza JC, Menne B (2009) Climate change and infectious diseases in Europe. Lancet Infect Dis 9(6):365-375

Seltenrich N (2018) Safe from the storm: creating climate-resilient health care facilities. Environ Health Perspect. https://doi. org/10.1289/EHP3810

Shimpo N, Wesener A, McWilliam W (2019) How community gardens may contribute to community resilience following an earthquake. Urban For Urban Green 38:124-132. https://doi.org/10.1016/j. ufug.2018.12.002

Sunstein CR (2006) The availability heuristic, intuitive cost-benefit analysis, and climate change. Clim Chang 77(1-2):195-210. https ://doi.org/10.1007/s10584-006-9073-y

Tariverdi M, Fotouhi H, Moryadee S, Miller-Hooks E (2019) Health care system disaster-resilience optimization given its reliance on interdependent critical lifelines. J Infrastruct Syst 25(1):04018044. https://doi.org/10.1061/(ASCE)IS.1943-555X.0000465

Tidball K (2012) Urgent biophilia: human-nature interactions and biological attractions in disaster resilience. Ecol Soc. https://doi. org/10.5751/ES-04596-170205

U.S. Climate Resilience Toolkit (USCRT) (2016) Building health care sector resilience. National Oceanographic and Atmospheric Administration, Washington, DC. https://toolkit.climate.gov/topic s/human-health/building-climate-resilience-health-sector

Verheul ML, Dückers ML (2020) Defining and operationalizing disaster preparedness in hospitals: a systematic literature review. Prehosp Disaster Med 35(1):61-68. https://doi.org/10.1017/S1049 023X19005181

World Health Organization (WHO) (2018) WHO health evidence network synthesis report: What quantitative and qualitative methods have been developed to measure health-related community resilience at a national and local level. World Health Organization, Copenhagen. https://apps.who.int/iris/handle/10665/326228

Yang Y, Peng F, Wang R, Guan K, Jiang T, Xu G, Chang C (2020) The deadly coronaviruses: the 2003 SARS pandemic and the 2020 novel coronavirus epidemic in China. J Autoimmun 109(1):102434. https://doi.org/10.1016/j.jaut.2020.102434

Young OR (2010) Institutional dynamics: resilience, vulnerability and adaptation in environmental and resource regimes. Glob Environ Change 20(3):378-385. https://doi.org/10.1016/j.gloen vcha.2009.10.001

Zhong S, Clark M, Hou XY, Zang Y, FitzGerald G (2014) Validation of a framework for measuring hospital disaster resilience using factor analysis. Int J Environ Res Public Health 11(6):6335-6353. https://doi.org/10.3390/ijerph110606335 